\title{
Centralization, Decentralization and Incentive Problems in Eurozone Financial Governance: A Contract Theory Analysis
}

\author{
Yutaka Suzuki ${ }^{1}$ \\ ${ }^{1}$ Faculty of Economics, Hosei University, Tokyo, Japan \\ Correspondence: Yutaka Suzuki, Faculty of Economics, Hosei University, 4342 Aihara Machida Tokyo 194-0298 \\ Japan. Tel: 81-42-783-2565. E-mail: yutaka@ @osei.ac.jp
}

Received: December 24, 2017

Accepted: January 30, 2018

Online Published: February 5, 2018

doi:10.5539/ijef.v10n3p93

URL: https://doi.org/10.5539/ijef.v10n3p93

\begin{abstract}
This paper uses a contract theory framework to analyze the mechanisms of eurozone financial governance, with a focus on centralization vs. decentralization and incentive problems. By constructing a Stackelberg game model with $\mathrm{n}$ Ministries of Finance as the first movers and the European Central Bank as the second mover, we show that each government can create growth in its own country (self-benefit) by increasing government spending, but that this will increase inflation, resulting in a decrease in the value of the euro. As these effects are shared equally by eurozone countries (cost sharing), an incentive to free-ride at the expense of other countries is present. We then analyze a penalty-based solution to the free-rider problem and derive a second-best solution where a commitment not to renegotiate penalties ex-post is impossible. The optimal solution shows that "limited sovereignty," that is, substantially constrained fiscal sovereignty, should be imposed as a high marginal cost for the issuance of public debt. Finally, we close the paper by discussing the possibility of Fiscal Integration (Fiscal Union).
\end{abstract}

Keywords: monetary centralization, fiscal decentralization, free-rider problem, penalty schemes and renegotiation, Stability and Growth Pact (SGP), fiscal integration

\section{Introduction}

This paper analyzes the mechanisms of eurozone financial governance through the Stability and Growth Pact (SGP) (and the Fiscal Compact (2012) as a revised form) in theory and in reality, with a focus on centralization, decentralization, and incentive structures.

We begin by describing the institutional framework of the period from 2002 to 2003, when the eurozone consisted of 12 countries (Note 1).

The authority on interest policy is centralized with the European Central Bank (ECB), and the authority on fiscal policy is decentralized, resting with each country. Thus, the eurozone has a structure of monetary centralization and fiscal decentralization under a common currency (the euro). Thus, a structure of strategic interdependence emerges, with tension between "the interest rate policy set by the ECB to maintain the value of the euro" and "national deficits incurred by each country".

The major factor making fiscal stabilization difficult is the "Prisoner's Dilemma" problem of financial governance. When other countries abide by fiscal rules, one country has an incentive to become a free rider. That country's neglect may cause other countries to follow, resulting in a loss of the force binding the SGP together. This may lead to further difficulties in maintaining the value of the euro, illustrating the theoretical phenomenon of "Tragedy of the Commons".

The SGP is the mechanism of financial governance under an environment of fiscal decentralization, which imposes on member nations the condition of "an annual national deficit below $3 \%$ of GDP, and a government debt of lower than $60 \%$ of GDP", at a regional level.

As an institutional mechanism for the SGP, the European Commission (EC) is allowed to act as an agent monitoring the national deficits of eurozone countries, and the EC has the authority to warn countries in violation of the rules that penalties will be applied.

The European Commission (EC) checks for divergence from the financial stabilization plans that member 
nations have submitted. This serves as an early warning of any risk of exceeding the $3 \%$ of GDP limit. The European Commission (EC) employs excessive national deficit procedures (EDP) to guard against the continuation or worsening of deficits. These procedures require measures to be taken within four months and a resolution to be reached within one year. A penalty warning is given for breaches.

The penalty is prescribed as a maximum of $0.5 \%$ of GDP. When the amount of the penalty is adopted by a vote of the Eurozone Finance Ministers Council, the penalty becomes binding.

This governance structure is divided, with the European Commission (EC) holding the warning authority regarding penalty application and the Eurozone Finance Ministers Council holding the decision-making authority. Therefore, a country in violation can approach the Ministry of Finance in each country to attempt to avoid having to pay a "huge" penalty, i.e., there is room for renegotiation.

Whether the penalty is indeed imposed is determined by qualified majority voting (QMV) in the Finance Ministers Council. Adoption of the penalty requires a two-thirds or greater number of votes, with the result that a minority of one-third or more votes can block the penalty. This means that it may be relatively easy for a major power in violation to form a blocking minority.

Two real cases from 2002 and 2003 exposed these institutional limitations.

Case 1: Decision not to adopt an early warning against Germany, January 30, 2002.

The European Commission (EC) issued an early warning. However, Germany was able to secure a blocking minority. To avoid the loss of credibility of the SGP that would result from a defeat in a vote, the Finance Ministers Council did not adopt the warning issued by the European Commission in exchange for a commitment from Germany to reduce its national deficit.

Case 2: Rejection of the warning against France and Germany by the Eurozone Finance Ministers Council, November, 2003.

France and Germany had been issued second warnings of excessive national deficit procedures (EDP), but the warning to reduce their national deficits was rejected by the QMV. A proposal was passed to issue a temporarily shelved penalty to Germany.

These two cases expose certain institutional limitations, demonstrating that even if the penalty included in the SGP is recommended by the European Commission (EC), it is extremely difficult for that penalty to be adopted by the Finance Ministers Council, which determines whether the penalty should actually be invoked.

The voting procedure that enabled the above renegotiation in 2002-2003 has recently been changed. In the new Reverse Qualified Majority Voting (RQMV) procedure set out in the Fiscal Compact in 2012, Eurozone member nations must present a qualified majority (a two-thirds or greater number of votes) to prevent the imposition of sanctions, rather than to support the imposition of sanctions as in the former Stability and Growth Pact (GSP). This change has made it more difficult for deviating countries to block the imposition of sanctions (penalties) by colluding with other countries, as blocking now requires a two-thirds or greater number of votes in the new RQMV procedure. We present a theoretical model to analyze the effect of this institutional change from QMV to RQMV.

We further view this process as a game structure in which the European Central Bank (ECB) raises the policy rate to maintain the value of the euro against any free-rider nation that accumulates national deficits when the penalty function of the SGP to suppress a national deficit under fiscal decentralization does not work.

Based on the above description, the following figure depicts the institutional framework of the Eurozone. 
Monetary Centralization, Fiscal Decentralization and

Eurozone Financial Governance through the Stability and Growth Pact (SGP)

(SGP operator)

European Commission

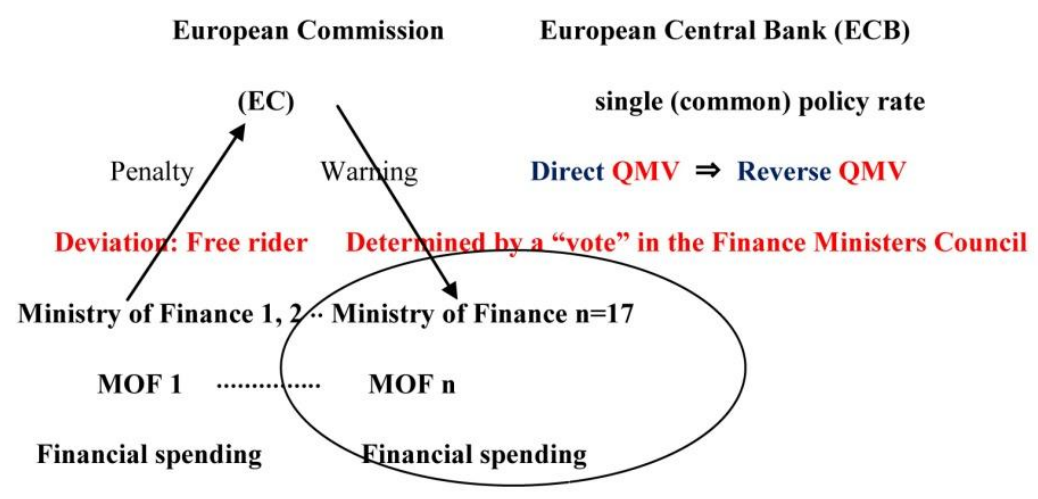

$\Rightarrow$ Fiscal Compact (2012.3) 
model of the monetary union. In the non-cooperative equilibrium, expecting the monetary authority to inflate nominal debt, the government tends to over-issue debt, weighing only the cost of inflation for its residents and ignoring the cost of inflation borne by the other members of the monetary union. Our paper adopts a simpler contract/game theory framework which still contains a similar free-rider problem, although the monetary authority maintains its commitment to price stability. Further, one of the important issues in the design of the monetary union is the question of the necessity of fiscal constraints. Chari and Kehoe (2007) showed that debt constraints are desirable in an environment without commitment on the part of the monetary authority. In contrast, our paper derives "limited sovereignty" as the optimal solution, indicating that substantially constrained fiscal sovereignty is an ex-ante solution for ex-post renegotiation of the penalty scheme.

\section{Basic Model Using Contract/Game Theory}

\subsection{Model Setting}

The member players of the European Union (EU) are the European Central Bank (ECB) and the Ministry of Finance (MOF) of each nation. The European Central Bank (ECB) is an integrated organization made up of the central banks of member nations, with the responsibility to manage monetary policy in an integrated manner and to determine the policy rate (common interest rate) $i$ (Note 3). However, the Ministry of Finance (MOF) of each nation has the authority to control its own financial spending. Thus, let the financial spending level of the nation $k$ be $d_{k}, k=1,2, \ldots, n$, This is a structure of monetary centralization and fiscal decentralization. The GDP (Gross Domestic Product, i.e., output) of nation $k$ is expressed as $x_{k}=d_{k}-i, k=1,2, \ldots, n$, which represents financial spending (financing through the issuance of national bonds) minus the policy rate $i$ (Note 4 ). The inflation rate $\pi_{k}$ of the nation $k$ is expressed as $\pi_{k}=d_{k}-\beta i, k=1,2, \ldots, n$ (Note 5), and we assume that $\beta>1$ (Note 6). Note that because inflation represents price increases, this is equivalent to a decrease in monetary value, that is, "the value of the euro".

Next, let the objective function of the nation $k$ 's Ministry of Finance (MOF) be $x_{k}-\frac{\alpha}{2}\left(d_{k}\right)^{2}$. This means that nation $k$ 's MOF places high value on an increase in GDP, i.e., the so called "economic growth" $x_{k}$, and that the issuance of public debt and increases in outstanding public debt will increase costs $\frac{\alpha}{2}\left(d_{k}\right)^{2}$ for the MOF. The interpretation of the issuance cost of public debt $\frac{\alpha}{2}\left(d_{k}\right)^{2}$ is as follows. $\alpha$ is the interest rate for public debt, and also a parameter that characterizes the marginal cost of the issuance of public debt. $\frac{\left(d_{k}\right)^{2}}{2}$ is the cost of obtaining the approval or acceptance of the parliament to increase the issuance of public debt (government financial spending). This means that increasing public debt $d_{k}$ is costly in two ways.

Meanwhile, let the objective function of the European Central Bank (ECB) be $-\mu \pi^{2}-\frac{\alpha}{2} \sum_{k=1}^{n}\left(d_{k}\right)^{2}$. As the ECB is a "guardian of commodity prices" with the mission to "maintain the value of the euro", the first term quadratic loss $-\mu \pi^{2}$ means that inflation/deflation (price increases/decreases) and changes in the value of the euro are viewed as costs for the ECB. Here, $\mu$ is a parameter that captures the social cost of inflation. The second term means that the ECB also recognizes the amount of government debt of each nation as a cost. The most important point is that the MOF acts based on an economic-expansion bias, in the sense that the MOF's objective includes $x$ (GDP growth) but not $-\mu \pi^{2}$ (cost of inflation), while the European Central Bank (ECB) has a price-stability (stability of the euro's value) bias in the sense that the ECB's objective includes $-\mu \pi^{2}$ but not $x$ (Note 7). In summary, a conflict of interest exists between the MOF and the ECB.

We have specified the players of the game (Ministries of Finance $k=1,2, . ., n$, European Central Bank), the strategies of each player (financial spending through the issuance of public debt $d_{k}, k=1,2, \ldots, n$ and a single policy rate $i$ ), and the objectives that each player pursues. As for the time structure (timing), the MOF of each country simultaneously and independently chooses its own financial spending $d_{1}, d_{2}, \ldots, d_{N}$, and, after observing 
this, the European Central Bank chooses a common policy rate $i$. The policy rate can be adjusted much more quickly than financial spending (the issuance of public debt).

Section 2.2 theoretically describes the following basic mechanism. The government in each country can create economic growth in that country, meaning an increase in GDP (100\% self-benefit), by increasing government spending. This will increase inflation and decrease the value of the euro. These effects are shared equally by euro countries (costs are shared equally). Thus, an incentive for cutting corners on reducing the issuance of public debt (i.e., a free ride at the expense of other countries).

\subsection{Model Solution by Backward Induction}

In this section, we solve the basic model using backward induction in one MOF case, two MOF cases, and $n$ MOF cases, and note that the "free-rider problem" occurs in equilibrium under the common currency (euro) system.

\subsection{1 $1 \mathrm{MOF}$ and ECB}

Timing (Note 8):

$\mathbf{T}=\mathbf{1}$ The Ministry of Finance (MOF) chooses financial spending $d$.

$\mathbf{T}=\mathbf{2}$ The European Central Bank (ECB) chooses the interest rate (policy rate) $i$

This is the Stackelberg Game played by the Ministry of Finance (MOF) and the European Central Bank (ECB).

T=2: Given the financial spending $d$ in $\mathrm{T}=1$, the ECB chooses the interest rate (policy rate) $i$.

$$
\max _{\{i\}}-\mu \pi^{2}-\alpha \frac{d^{2}}{2}
$$

Substituting $\pi=d-\beta i$ into the payoff function and optimizing with respect to $i$, we have the First-order condition for optimality: $d-\beta i=0$

Therefore, the best response function by the ECB in $\mathrm{T}=2$ is $i^{*}(d)=\frac{d}{\beta}$

This shows that inflation (the decrease in the value of the Euro) due to the increase in financial spending $d$ in $\mathrm{T}=1$ is suppressed by the policy rate $i$ in $\mathrm{T}=2$.

$\mathbf{T}=\mathbf{1}$ : The Ministry of Finance (MOF) expects the best response function by the European Central Bank (ECB) in $\mathrm{T}=2$ and chooses the optimal financial spending.

$$
\max _{\{d\}} x-\alpha \frac{d^{2}}{2}=\left(d-i^{*}(d)\right)-\alpha \frac{d^{2}}{2} \quad \text { s.t. } i^{*}(d)=\frac{d}{\beta}
$$

That is, the Ministry of Finance (MOF) solves $\max _{\{d\}}\left(d-\frac{d}{\beta}\right)-\alpha \frac{d^{2}}{2}$

The First-order condition for optimality is $\left(1-\frac{1}{\beta}\right)-\alpha d=0$

Hence, the optimal solution in $\mathrm{T}=1$ is $d^{*}=\frac{1}{\alpha}\left(1-\frac{1}{\beta}\right)$ and the equilibrium policy rate set by the ECB in $\mathrm{T}=2$ is $i^{*}=\frac{1}{\alpha \beta}\left(1-\frac{1}{\beta}\right)$. The solution concept is Sub-game Perfect Equilibrium, which corresponds to $d^{*}=\frac{1}{\alpha}\left(1-\frac{1}{\beta}\right)$ and $i^{*}(d)=\frac{d}{\beta}$.

Note: The Nash Equilibrium of a Simultaneous Move Game between MOF and ECB is $d^{N}=\frac{1}{\alpha}, i^{N}=\frac{1}{\alpha \beta}$, higher than in the case of the Stackelberg Game. In the Stackelberg game, the follower (ECB), after observing the leader's (MOF) move (the fiscal spending at $\mathrm{T}=1$ ), cancels out some of the effect of the increase in GDP by 
increasing the policy rate $i^{*}(d)=\frac{d}{\beta}$. Expecting this, the MOF only adopts the optimal fiscal expenditure (the issuance of public debt) to maximize $x-\alpha \frac{d^{2}}{2}=\left(d-i^{*}(d)\right)-\alpha \frac{d^{2}}{2}$. In other words, the ECB has the authority to increase the policy rate, suppressing the incentive for the MOF to increase fiscal spending in $\mathrm{T}=1$ (Note 9 , Note 10).

Let us review the argument thus far using the best response functions. The best response function for the ECB $i^{*}(d)=\frac{d}{\beta}$ is depicted in Figure 1. Expecting this, the MOF chooses the optimal fiscal spending level $d^{*}=\frac{1}{\alpha}\left(1-\frac{1}{\beta}\right)$ at $\mathrm{T}=1$, which maximizes the difference between $d-\alpha \frac{d^{2}}{2}=d\left(1-\alpha \frac{d}{2}\right)$ and $i^{*}(d)=\frac{d}{\beta}$. We can confirm that the marginal benefit $1-\alpha d$ obtained by increasing $d$ is balanced by the marginal increase in the optimal response $\frac{1}{\beta}$ at $d^{*}=\frac{1}{\alpha}\left(1-\frac{1}{\beta}\right)$. The equilibrium interest rate is then $i^{*}\left(d^{*}\right)=\frac{1}{\alpha \beta}\left(1-\frac{1}{\beta}\right)$. We depict this Stackelberg equilibrium point as S1 (for one MOF case). The Nash equilibrium point in Figure 1 is N.

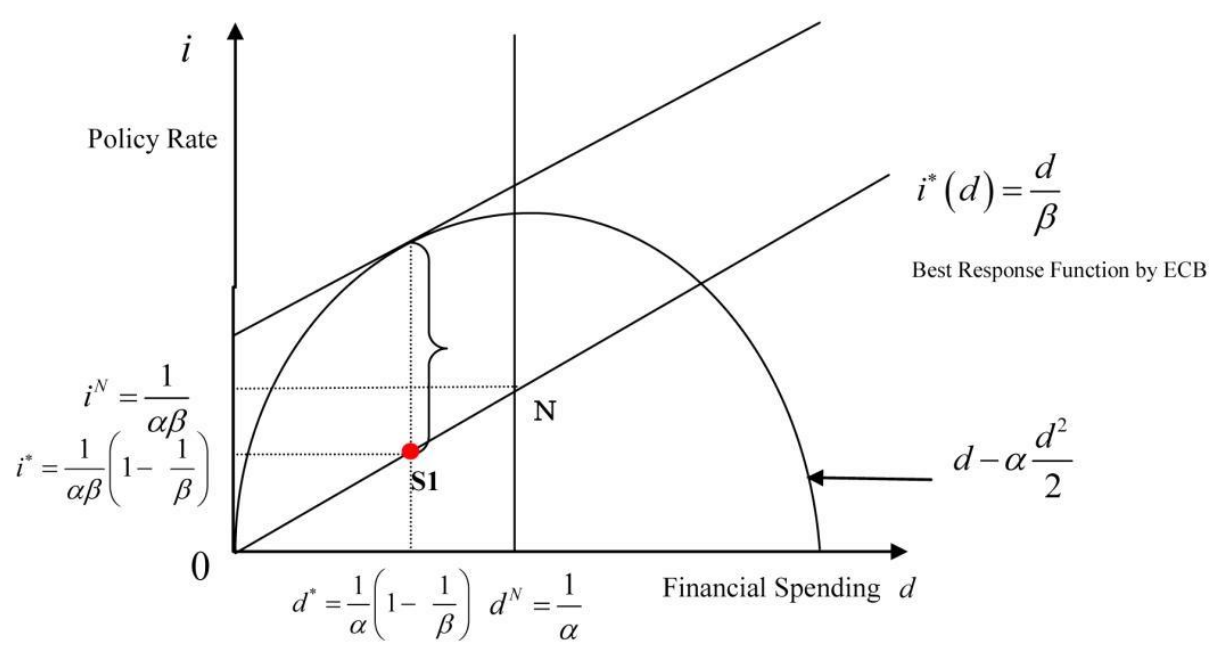

Figure 1. Stackelberg equilibrium point S1: $1 \mathrm{MOF}$ and ECB

\subsubsection{MOFs and ECB}

The time line is as follows, and we solve this game by backward induction.

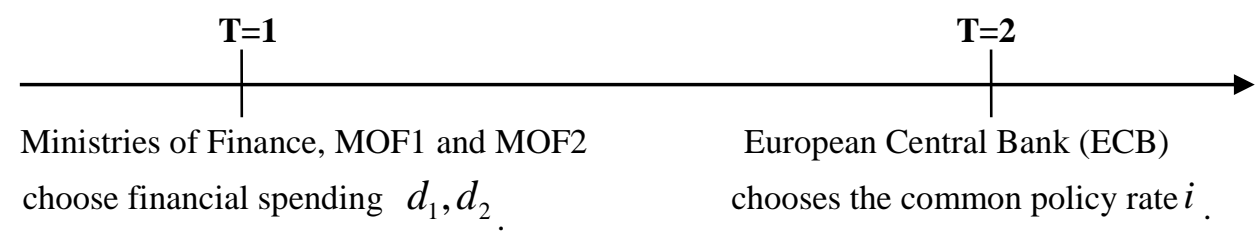

T=2: Given the financial spending $d_{1}, d_{2}$ of MF1 and MF2, the ECB chooses the interest rate (policy rate) $i$. Given the first period of financial expenditure $d_{1}, d_{2}$, and in accordance with the common policy rate $i$, which the $\mathrm{ECB}$ chooses at $\mathrm{T}=2$, the expected inflation rate in countries $k=1,2$ at $\mathrm{T}=2$ is $\pi_{k}=d_{k}-\beta i, k=1,2$. As the average inflation rate is $\frac{\pi_{1}+\pi_{2}}{2}=\frac{d_{1}+d_{2}}{2}-\beta i$, the ECB solves the following problem. 


$$
\max _{\{i\}}-\mu\left(\frac{\pi_{1}+\pi_{2}}{2}\right)^{2}-\alpha \frac{d_{1}^{2}+d_{2}^{2}}{2} \Leftrightarrow \max _{\{i\}}-\mu\left(\frac{d_{1}+d_{2}}{2}-\beta i\right)^{2}-\alpha \frac{d_{1}^{2}+d_{2}^{2}}{2}
$$

The First Order Condition for optimality is $\frac{d_{1}+d_{2}}{2}-\beta i=0$.

Thus, the best response function by the ECB at T=2 is $i^{*}\left(d_{1}, d_{2}\right)=\frac{1}{\beta} \frac{d_{1}+d_{2}}{2}$.

This means that the optimal action for the ECB is to increase the policy rate $i$ in proportion to the average increase in inflation (meaning a decrease in the value of the euro) due to the increase in the first period of average financial spending $\frac{d_{1}+d_{2}}{2}$.

T=1: The Ministry of Finance in each country $k=1,2$ expects the optimal response by the European Central Bank (ECB) at $\mathrm{T}=2$ and simultaneously chooses the optimal level of financial spending.

The problem is $\max _{\left\{d_{k}\right\}} x_{k}-\alpha \frac{d_{k}^{2}}{2}=\left(d_{k}-i^{*}\right)-\alpha \frac{d_{k}^{2}}{2}, k=1,2 \quad$ s.t. $i^{*}=\frac{1}{\beta} \frac{d_{1}+d_{2}}{2}$

Optimizing $x_{k}-\alpha \frac{d_{k}^{2}}{2}=\left(d_{k}-\frac{1}{\beta} \frac{d_{k}+d_{-k}}{2}\right)-\alpha \frac{d_{k}^{2}}{2}$ with respect to $d_{k}, k=1,2$, we have the First Order Condition: $\left(1-\frac{1}{\beta} \frac{1}{2}\right)-\alpha d_{k}=0$. The solution is $d_{k}^{*}=\frac{1}{\alpha}\left(1-\frac{1}{2 \beta}\right), k=1,2 \quad$ (Note 11)

Thus, the Sub-game Perfect Equilibrium of this game is $d_{k}^{*}=\frac{1}{\alpha}\left(1-\frac{1}{2 \beta}\right), k=1,2$, and $i^{*}\left(d_{1}, d_{2}\right)=\frac{1}{\beta} \frac{d_{1}+d_{2}}{2}$

We see that if there are two Ministries of Finance, equilibrium financial spending at $\mathrm{T}=1$ increases $\left(d_{k}^{*}=\frac{1}{\alpha}\left(1-\frac{1}{2 \beta}\right)>d^{*}=\frac{1}{\alpha}\left(1-\frac{1}{\beta}\right)\right.$, and the policy rate determined by the ECB at $\mathrm{T}=2$ also increases $\left(i^{*}\left(d_{1}^{*}, d_{2}^{*}\right)=\frac{1}{\alpha \beta}\left(1-\frac{1}{2 \beta}\right)>i^{*}\left(d^{*}\right)=\frac{1}{\alpha \beta}\left(1-\frac{1}{\beta}\right)\right)$.

\section{Intuitive Explanation}

While a country's GDP is increased by $100 \%$ of any increase in financial spending by the MOF of that country, the increase in interest rates (inflation offset by an increase in interest rates) by the ECB at $\mathrm{T}=2$ will be half of that when there is only one Ministry of Finance. Thus, the costs of the euro falling due to inflation are equally shared by the two countries. Then, the $100 \%$ self-benefit vs. the $50 \%$ cost burden will lead to the "free-rider problem", that is, an excessive financial incentive to spend. An incentive exists to limit reductions in the issuance of public debt (i.e., there is an incentive to free ride at the expense of other countries).

We will now express this in a simple mathematical way. Each MOF $k=1,2$ simultaneously solves the following problem at $\mathrm{T}=1: \max _{\left\{d_{k}\right\}}\left(d_{k}-i^{*}-\alpha \frac{d_{k}^{2}}{2}\right)$ s.t. $i^{*}=\frac{1}{\beta} \frac{d_{1}+d_{2}}{2}$

The first order condition for optimality of $d_{k}$ is $1-\frac{1}{\beta} \frac{1}{2}-\alpha d_{k}=0$

Rearranging the left hand side of the equation, we obtain $\underbrace{1-\alpha d_{k}}_{\mathrm{MR}}-\underbrace{\partial i^{*} / \partial d_{k}}_{\mathrm{MC}}=\underbrace{1-\alpha d_{k}}_{100 \%}-1 / 2 \beta$.

While the GDP of this country is increased by $100 \%$ of the increase in financial spending, that is, by $1-\alpha d_{k}$, the increase in interest rates (inflation offset by an increase in interest rates) at $\mathrm{T}=2$ by the ECB is one half of the increase when there is one Ministry of Finance $(1 / 2)(1 / \beta)$. As the costs of the euro decreasing in value due to inflation are equally shared by two nations, the free rider problem (excessive fiscal spending) appears. We depict the equilibrium point as $\mathbf{S 2}$ (for the two MOF case) in Figure 2. 


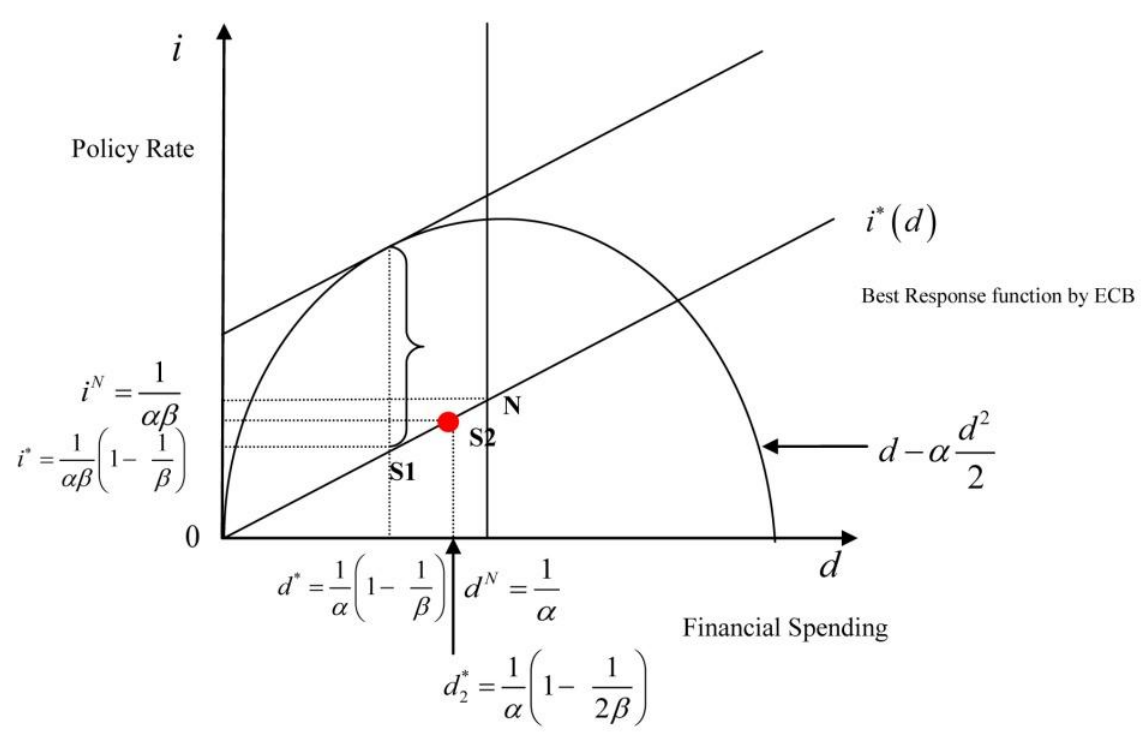

Figure 2. Stackelberg equilibrium point S2: 2 MOFs and ECB

\subsection{3 n MOFs and ECB}

What happens if the number of Ministries of Finance (MOF) (or the number of nations) $n$ increases? Then, each MOF simultaneously solves the following problem at $\mathrm{T}=1$

$$
\max _{\left\{d_{k}\right\}}\left(d_{k}-i^{*}-\alpha \frac{d_{k}^{2}}{2}\right) \text { s.t. } i^{*}=\frac{1}{\beta} \frac{d_{1}+d_{2}+\cdots+d_{n}}{n}
$$

The first order condition for the optimality of $d_{k}$ is $1-\frac{1}{\beta} \frac{1}{n}-\alpha d_{k}=0$

Rearranging the left hand side, we have $\underbrace{1-\alpha d_{k}}_{\mathrm{MR}}-\underbrace{\partial i^{*} / \partial d_{k}}_{\mathrm{MC}}=\underbrace{1-\alpha d_{k}}_{100 \%}-\underset{1 / n \text { of SMC }}{1 / n \beta}$

While the GDP of a country is increased by $100 \%$ of the increase in financial spending, that is, by $1-\alpha d_{k}$, the increase in interest rates (inflation offset by an increase in interest rates) by the ECB in the second period is one $\mathbf{n}^{\text {th }}$ the increase observed when there is one Ministry of Finance, that is, $(1 / n)(1 / \beta)$. The costs of the euro falling due to inflation are shared equally by $\mathrm{n}$ nations. Thus, the free rider problem will be more severe. Indeed we reach the Subgame Perfect Equilibrium Solution $d_{k}^{*}=\frac{1}{\alpha}\left(1-\frac{1}{n \beta}\right), k=1,2, . ., n$ and $i^{*}=\frac{1}{\alpha \beta}\left(1-\frac{1}{n \beta}\right)$, which increases as $n$ increases (Note 12).

Summarizing the argument presented in this section, we make the following proposition.

\section{Proposition1}

Under the common currency union with Monetary Centralization and Fiscal Decentralization, the free-rider problem for the issuance of public debt (excessive fiscal spending) occurs in equilibrium. As a result, the equilibrium policy interest rate also increases. As the number of Eurozone member countries increases, the free-rider problem becomes more severe.

This proposition implies that under such a governance structure that no fiscal rules (penalty schemes) are enforced among Eurozone countries, member countries always have the incentive to over-spend, boosting domestic GDP at the cost of common currency's sustainability. This is just the classical "tragedy of the commons". That is, the explosion of public debt may bring down the common currency, followed by break-up of the currency union. 


\section{Penalty Scheme in the Stability and Growth Pact (SGP): Commitment vs. Renegotiation}

\subsection{Commitment Solution to the Free Rider Problem (Benchmark)}

When only one country deviates from the agreement, that country pays penalty charges $F$ to the European Commission (EC). When another country deviates, the deviating country pays the penalty charges $F$ to the European Commission (EC), while compliant countries receive the charges split among $n-1$ countries.

Thus, a country faces the following penalty scheme: $s_{k}(\mathbf{d})=\left\{\begin{array}{cl}-F & \text { if } \\ F /(n-1) & \text { if }\end{array}\right.$ One of the other countries deviates

where $\mathbf{d}=\left(d_{1}, d_{2}, \ldots, d_{n}\right)$ is the vector of fiscal spending $d_{k}$ by each country $k=1,2, . ., n$

When an executor exists who commits himself to and enforces such schemes where a penalty is imposed on countries that deviate and the penalties (payments) are transferred to those countries that abide by the rules, the first best solution can be achieved (Note 13).

3.2 What Is Supposed to Happen When a Commitment not to Conduct Ex-Post Renegotiation of the Penalty Is Impossible?

As discussed in the introduction, in real-life scenarios, "re-discussion (voting)" was conducted to determine whether penalties should be imposed on the deviating countries. When the major powers Germany and France broke the fiscal rule of the SGP (by excessive government spending), ex-post renegotiation occurred. At that time, the countries involved were able to gain from the renegotiation. In exchange for side payments to other countries by Germany and France, no large penalty $(F)$ was assessed, with a significant reduction in the amount of the penalty. Therefore, we propose the following hypothesis.

Hypothesis: Let the bargaining power of the European Commission (EC) be $\lambda \in[0,1]$, and the bargaining power of all remaining n-1 member nations be $1-\lambda$. When Germany (and France) "follows and accepts" the penalty, the penalty $F$ is paid to the European Commission (EC) and then allocated to the European Commission (EC) and the other $n-1$ countries in the portion of $\lambda: 1-\lambda$. When the penalty is "not followed" and the side payment $(1-\lambda) F$ is paid to the remaining $\mathrm{n}-1$ member nations after direct renegotiation, the offer from the deviating country is accepted (Note 14) by the n-1 nations, decreasing the payment by the deviating country by $F-(1-\lambda) F=\lambda F \geq 0$. This is the same as the idea of "bid-rigging in tendering" or "collusion in an auction". This weakens the ex-post penalty scheme and makes it more difficult to suppress ex-ante fiscal incentives at the proper level.

We now analyze to what degree fiscal discipline can be maintained through this "penalty scheme with ex-post renegotiation".

Partial analysis: We focus on a case where equilibrium renegotiation is induced, led by country $\alpha_{L}$ (Note 15).

Let $d_{k}^{*}=\frac{1}{\alpha_{k}}\left(1-\frac{1}{2 \beta}\right), k=L, H$ be the dominant strategy (Nash) equilibrium financial spending level of types $\alpha_{L}, \alpha_{H}$ (Note 16) when there are two countries, $n=2\left(\alpha_{L}, \alpha_{H}\right)$.

Letting $\bar{d}_{H}$ be the financial spending level of country $\alpha_{H}$, which the SGP intends to support (i.e., fiscal budget), $\bar{d}_{H} \leq d_{H}^{*}=\frac{1}{\alpha_{H}}\left(1-\frac{1}{2 \beta}\right) \quad$ (the free-rider level) should be satisfied. Then, the amount of the penalty $F$ is set while considering that country $\alpha_{L}$ deviates from the SGP and renegotiation occurs between countries $\alpha_{L}$ and $\alpha_{H}$ (Note 17).

Now, we have the incentive constraint for country $\alpha_{H}$ to support the financial spending (fiscal budget) level $\bar{d}_{H}$ suggested by the SGP

$$
\Delta_{H} \leq 0 \Leftrightarrow \frac{1}{2 \alpha_{H}}\left(1-\frac{1}{2 \beta}\right)^{2}-\underbrace{(1-\lambda) F}_{\text {Substantial Penalty }} \leq \frac{\alpha_{H}}{2} \bar{d}_{H}\left[\frac{2}{\alpha_{H}}\left(1-\frac{1}{2 \beta}\right)-\bar{d}_{H}\right]
$$




$$
\Leftrightarrow \underbrace{\frac{1}{2 \alpha_{H}}\left(1-\frac{1}{2 \beta}\right)^{2}-\left[\bar{d}_{H}\left(1-\frac{1}{2 \beta}\right)-\frac{\alpha_{H}}{2}\left(\bar{d}_{H}\right)^{2}\right]}_{\text {Deviation Gain from } \bar{d}_{H} \text { to } d_{H}^{*}} \leq \underbrace{(1-\lambda) F}_{\text {Substantial Penalty }}
$$

To support the financial spending level of at least $\bar{d}_{H}$, the amount of the penalty $F$

$$
(1-\lambda) F=\underbrace{\frac{1}{2 \alpha_{H}}\left(1-\frac{1}{2 \beta}\right)^{2}-\left[\bar{d}_{H}\left(1-\frac{1}{2 \beta}\right)-\frac{\alpha_{H}}{2}\left(\bar{d}_{H}\right)^{2}\right]}_{\text {Deviation Gain from } \bar{d}_{H} \text { to } \bar{d}_{H}^{*}}
$$

is required and is defined as $\mathrm{F}\left(\bar{d}_{H}\right)$. Comparative statistics yield $\Delta \mathrm{F}\left(\bar{d}_{H}\right) / \Delta \bar{d}_{H}<0$, indicating that to reduce the financial spending level $\bar{d}_{H}$ or enhance the fiscal discipline of country $\alpha_{H}$, the amount of the penalty $F$ should be increased.

Now, when the incentive constraint for country $\alpha_{H}$ is binding (holding equal), country $\alpha_{L}$ has an incentive to deviate to the equilibrium dominant strategy level $d_{L}^{*}=\frac{1}{\alpha_{L}}\left(1-\frac{1}{2 \beta}\right)$ against $(1-\lambda) \mathrm{F}\left(\bar{d}_{H}\right)$ and $\bar{d}_{L}$ suggested for country $\alpha_{L}\left(\leq \alpha_{H}\right)$, resulting in the failure to satisfy the incentive constraint on country $\alpha_{L}$. That is, $\Delta_{L} \geq 0$ (Note 18), specifically:

$$
\underbrace{\frac{1}{2 \alpha_{L}}\left(1-\frac{1}{2 \beta}\right)^{2}-\left[\bar{d}_{L}\left(1-\frac{1}{2 \beta}\right)-\frac{\alpha_{L}}{2}\left(\bar{d}_{L}\right)^{2}\right]}_{\text {Deviation Gain from } \bar{d}_{L} \text { to } d_{L}^{*}} \geq \underbrace{(1-\lambda) F\left(\bar{d}_{H}\right)}_{\text {Substantial Penalty }}
$$

At this time, a side-payment of $(1-\lambda) F\left(\bar{d}_{H}\right)$ emerges in the ex-post renegotiation between countries $\alpha_{L}$ and $\alpha_{H}$. For the side-payment from the country in violation to other countries in ex-post renegotiation, it is assumed that unnecessary spending (excess burden) $\xi \geq 0$ occurs for each unit (Note 19).

The total welfare in EU countries, which corresponds to financial spending levels $d_{L}^{*}$ and $\bar{d}_{H}(\leq) d_{H}^{*}$, is expressed by the following formula encompassing growth (economy, GDP), inflation, the costs of the issuance of public debt and the dead weight cost.

$$
\begin{aligned}
& \left(x_{L}-\alpha_{L} \frac{d_{L}^{2}}{2}\right)+\left(x_{H}-\alpha_{H} \frac{\bar{d}_{H}^{2}}{2}\right)-\mu\left(\frac{\pi_{L}+\pi_{H}}{2}\right)^{2}-\xi(1-\lambda) F\left(\bar{d}_{H}\right) \\
& =\underbrace{\left(d_{L}^{*}-i-\alpha_{L} \frac{\left(d_{L}^{*}\right)^{2}}{2}\right)+\left(\bar{d}_{H}-i-\alpha_{H} \frac{\left(\bar{d}_{H}\right)^{2}}{2}\right)}_{\text {(A) }}-\underbrace{\mu\left(\frac{d_{L}^{*}+\bar{d}_{H}}{2}-\beta i\right)^{2}}_{\text {(B) }}-\underbrace{\xi(1-\lambda) F\left(\bar{d}_{H}\right)}_{\text {(C) }}
\end{aligned}
$$

As the policy rate is chosen by the ECB so that $i=\frac{1}{\beta}\left(\frac{d_{L}^{*}+\bar{d}_{H}}{2}\right)$, the second term (B) is zero at equilibrium. The Stability and Growth Pact (SGP) sets the amount of the penalty $F$ so that the financial spending level $\bar{d}_{H}$ is sustained at equilibrium, where the difference between the first term, the total surplus (A) of the Ministries of Finance in both countries $\alpha_{L}, \alpha_{H}$ and the third term (C), the dead weight cost, will be maximized.

Now, we have the First Order Condition for optimality:

$$
\begin{aligned}
& -\frac{1}{2 \beta}+\left(1-\frac{1}{2 \beta}\right)-\alpha_{H} \bar{d}_{H}-\xi(1-\lambda) F^{\prime}\left(\bar{d}_{H}\right)=0 \\
& \Leftrightarrow \quad-\frac{1}{2 \beta}+\underbrace{\left(1-\frac{1}{2 \beta}\right)-\alpha_{H} \bar{d}_{H}}_{\begin{array}{c}
\text { marginal effect on the payoff } \\
\text { of MOF of } \alpha_{L} \text { country }
\end{array}}=\underbrace{\xi(1-\lambda) F^{\prime}\left(\bar{d}_{H}\right)}_{\begin{array}{c}
\text { marginal effect on the payoff } \\
\text { of MOF of } \alpha_{H} \text { country }
\end{array}}
\end{aligned}
$$


As the first-order condition for $\bar{d}_{H}$ shows, the fiscal discipline of $\mathrm{d}=\bar{d}_{H}$ and the required amount of the penalty $\mathrm{F}\left(\bar{d}_{H}\right)$ are determined so that the marginal increase in total surplus and the marginal increase in dead weight cost will be balanced.

Substituting $(1-\lambda) F^{\prime}\left(\bar{d}_{H}\right)=-\alpha_{H}\left\{\frac{1}{\alpha_{H}}\left(1-\frac{1}{2 \beta}\right)-\bar{d}_{H}\right\}$ into the above condition, we have an explicit solution for optimal fiscal discipline (fiscal budget) $\bar{d}_{H}^{*}$

$$
\bar{d}_{H}^{*}=\frac{1}{1+\xi} \underbrace{\frac{1}{\alpha_{H}}\left(1-\frac{1}{\beta}\right)}_{\text {FB level for } \mathrm{H}}+\frac{\xi}{1+\xi} \underbrace{\frac{1}{\alpha_{H}}\left(1-\frac{1}{2 \beta}\right)}_{\begin{array}{c}
\text { Dominant Strategy Level } \\
\text { for } \mathrm{H}
\end{array}}
$$

From $(*)$, we can determine the following. First, the targeted level of fiscal discipline $\bar{d}_{H}^{*}$ is weighted by the first best level and the dominant strategy level (the free-rider level) in the proportion of $1: \xi$. As $\zeta$ is larger, the divergence of $\bar{d}_{H}^{*}$ from the first best is more acceptable. This is interpreted to mean that as the dead weight cost $\zeta$ is larger when renegotiation occurs, the amount of the penalty cannot be increased.

Second, as $\alpha_{H}$ increases, maintaining the optimal fiscal discipline $\bar{d}_{H}^{*}$ for the high marginal cost country $\alpha_{H}$ becomes more difficult, i.e., it becomes more difficult to maintain the fiscal budget $\bar{d}_{H}^{*}$ assigned to country $\alpha_{H}$. This implies that when the high marginal cost country $\alpha_{H}$ loses the trust of the international bond market and the interest rate $\alpha_{H}$ for its public debt increases (the price decreases), the fiscal sovereignty of the high-cost country $\alpha_{H}$ should be limited. In this sense, the solution (*) optimally involves the idea of "limited sovereignty".

Third, as $\beta$ increases, the optimal fiscal discipline $\bar{d}_{H}^{*}$ for the high marginal cost country $\alpha_{H}$ increases, i.e., the fiscal budget $\bar{d}_{H}^{*}$ assigned to country $\alpha_{H}$ can be relaxed.

This can be interpreted as follows. When $\beta$ is higher, the ECB can suppress inflation sufficiently and stabilize the value of the Euro through the policy rate $i$ (Note 20). Therefore, it is not necessary to impose a hard budget to suppress the fiscal spending of country $\alpha_{H}$. Rather, the fiscal budget should be relaxed to induce economic growth.

Finally, as the European Commission (EC)'s portion $\lambda$ increases, the effect of the penalty scheme weakens because a country in violation can easily compensate countries with small side payments of substantive reallocation. Hence, the amount of the penalty $F$ becomes larger by the amount of the European Commission's portion $\lambda$.

The argument in this section is summarized in the following proposition and corollaries.

\section{Proposition2}

Under the Stability and Growth Pact (SGP), it may be impossible to honor a commitment not to renegotiate the penalty scheme ex post. Then, equilibrium renegotiation occurs ex-post, which is led by the low marginal cost country $\alpha_{L}$ for the issuance of public debt. The second best solution is an optimal fiscal discipline (fiscal budget) $\bar{d}_{H}^{*}$ for the high marginal cost country $\alpha_{H}$, which is set at the weighted average of the first best and dominant strategy (free-rider) levels. In this sense, the optimal solution involves the idea of "limited sovereignty" (Note 21).

\section{Corollary2.1 Effect of $\alpha_{H}$ on $\bar{d}_{H}^{*}$}

As the cost for the issuance of public debt (the interest rate of public debt) $\alpha_{H}$ becomes higher, the optimal fiscal discipline (fiscal budget) $\bar{d}_{H}^{*}$ for the high marginal cost country $\alpha_{H}$ becomes harder, i.e., the fiscal sovereignty of the high-cost country $\alpha_{H}$ should be more limited. As the interest rate of public debt $\alpha_{H}$ decreases, the limitation on fiscal sovereignty should be more relaxed.

Corollary 2.2 Effect of $\beta$ on $\bar{d}_{H}^{*}$

The better the ECB can suppress inflation and stabilize the value of the Euro through the policy rate, the more the optimal fiscal discipline (fiscal budget) $\bar{d}_{H}^{*}$ for the high marginal cost country $\alpha_{H}$ can be relaxed.

\section{Discussion}

\subsection{A Comment from Our Analysis on the First Eurozone Crisis in 2010 (Note 22)}

Although the Eurozone crisis emerged in early 2010 from Greece, our paper demonstrates its deep, fundamental roots. The $\mathrm{n}$ MOF-ECB model in section 2 indicates that a common currency with fiscal decentralization 
generates the economic cost of a severe free-rider problem, which takes the concrete form of higher fiscal spending than the best level through the issuance of public debt by each member nation (MOF). As this can result in a decrease in the value of the euro (and an increase in the interest rate on public debt), the SGP was established as a mechanism of fiscal governance to prevent such a free-rider problem.

In the Greek financial crisis, Greece (an $\alpha_{H}$ country) should have abided by the fiscal budget rule $d_{H} \leq \bar{d}_{H}$ in the SGP, but there was a large deviation $d_{H} \square \bar{d}_{H}$ which was hidden with "forged evidence". Eventually, the truth became clear to the market. This caused a sharp fall in prices and an increase in interest on Greek public debt. The difference in yield $\alpha_{H}-\alpha_{L}$ greatly increased, where $\alpha_{L}$ is the interest rate on public debt in Germany. As a result, Greece had to achieve $d_{H} \cong 0$, and its GDP decreased significantly. The collapse of the Greek economy has resulted in a dramatic loss of trust in the euro, which could result in the end of that currency. Thus, the ruin of the Greek economy was prevented (i.e., Greece was bailed out).

In August 2011, the slowdown in the world economy triggered concern about the solvency of much larger economies than Greece such as Spain and Italy. This extension of the crisis was reflected in rising interest rate spreads on public debt (above the interest rate on German public debt). During these few years, some defensive barriers were constructed against the sovereign crisis caused by Eurozone member nations (like Greece, Spain, and Portugal) to prevent the crisis from worsening. One representative barrier is the European Stability Mechanism (ESM), which has discretely reduced the possibility of the collapse of the Eurozone. Although there is still no simple solution to the Eurozone crisis, our analysis suggests the following practical prescription.

The ex-ante limited sovereignty (ex-ante power restriction) derived from the analysis of section 3 as the second best mode of fiscal discipline and the commitment to ex-post sanction (penalty) (commitment not to renegotiate it ex-post) will both be important. Of course, monitoring of the observance of the fiscal budget rule should be strengthened as proposed in the multilateral surveillance procedure.

\subsection{The Possibility of Fiscal Integration or Fiscal Union}

From Section 3, we found that under such governance structure that without a fiscal union as a companion to the monetary union, member countries are loosely subject to the penalty scheme in the Stability and Growth Pact, deviating countries cannot be credibly punished, especially if they are from the "core" countries. That is, without a fiscal union, a monetary union itself can hardly contain each member country's incentive of overspending through debt financing, which threatens the credibility of common currency Euro and may bring the entire monetary union to the brink of collapse. So, finally, we need to discuss the possibility of Fiscal Union (Fiscal Integration).

Fiscal Integration or Fiscal Union theoretically corresponds to the 1MOF + ECB model in section 2, where a Stackelberg Game is played between the Ministry of Finance (MOF) and the European Central Bank (ECB). The net payoff of this Regime is

$$
x-\mu \pi^{2}-\alpha \frac{d^{2}}{2}=d^{*}-i^{*}-\alpha \frac{d^{* 2}}{2}=\underbrace{\frac{1}{\alpha}\left(1-\frac{1}{\beta}\right)}_{d^{*}}-\underbrace{\frac{1}{\alpha \beta}\left(1-\frac{1}{\beta}\right)}_{i}-\frac{\alpha}{2} \frac{1}{\alpha^{2}}\left(1-\frac{1}{\beta}\right)^{2}=\frac{1}{2 \alpha}\left(1-\frac{1}{\beta}\right)^{2}
$$

This payoff is always larger than that of the Regime with "Fiscal Decentralization and Monetary Centralization" (2MOFs + ECB model) because the net payoff of Regime 3 is $\frac{1}{2 \alpha}\left(1-\frac{1}{2 \beta}\right)\left(1-\frac{3}{2 \beta}\right)$, and it follows that $\frac{1}{2 \alpha}\left(1-\frac{1}{\beta}\right)^{2}>\frac{1}{2 \alpha}\left(1-\frac{1}{2 \beta}\right)\left(1-\frac{3}{2 \beta}\right)$ for $\beta>1$

In Figure 3, Point FI represents Fiscal Integration (Fiscal Union) and the ECB equilibrium point, which has a greater net payoff than that of the Regime with "Fiscal Decentralization and Monetary Centralization" (Point S2). Economically, this means that the Financial Ministers Council (or unique fiscal budgetary authority) directly controls fiscal policies of all Eurozone member nations in order to internalize (free-riding) externalities among them. In other words, authority regarding financial policy itself should not be decentralized, but rather centralized into a unique fiscal budgetary authority. 


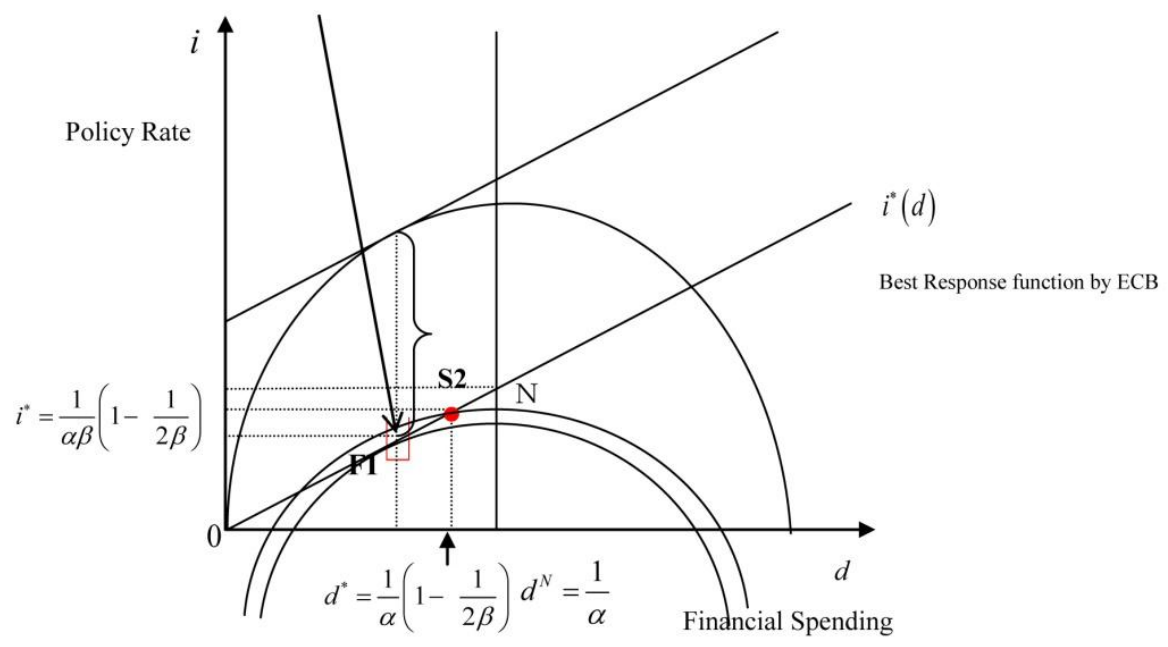

Figure 3. Fiscal integration (Fiscal Union) + ECB regime

Why is this regime unattainable? In the Eurozone financial governance, each member nation may derive some political benefit from its authority on fiscal policy and hesitate to delegate this fiscal authority (i.e., sovereignty) to some central authority, with the result that fiscal integration or fiscal union may not be achievable despite the fact that it would be more economically efficient. This point seems to be the same as that referred to in the literature of the Theory of the Firm regarding managers and workers who fear and resist losing their private benefits in a shift from Non-Integration to Integration (Note 23). Thus, we have the following Proposition 3.

\section{Proposition 3}

If the Fiscal Union holds, efficiency will be enhanced under relative sovereignty (by ECB and Fiscal Union) because the free-rider problem under fiscal decentralization can be solved through the internalization of externalities. However, the Fiscal Union would not hold if the loss of political benefits to each euro member nation due to the loss of fiscal sovereignty induced by the fiscal integration (Fiscal Union) were large enough to lead member nations to break away (Note 24).

\section{Concluding Remarks}

This paper used a game/contract theory framework to analyze the mechanisms of eurozone financial governance, with a focus on centralization vs. decentralization and incentive structures in the European Union (EU).

By constructing a Stackelberg game model played by $n$ Ministries of Finance (MOF) in the $n$ Euro zone member countries as the first movers, and the European Central Bank (ECB) as the second mover, we first expressed the basic intuition that the government of each country can create growth (economy) in that country, that is, increase GDP (100\% self-benefit), by increasing government spending, but that this will increase inflation and decrease the value of the euro. As these effects are shared equally by euro countries (the cost is shared equally), an incentive exists to avoid reducing the issuance of public debt, gaining a free ride at the expense of other countries.

Following this framework, we analyzed a solution to the free-rider problem through the penalty scheme in the SGP, and derived the second best solution when a commitment not to renegotiate penalties ex-post is impossible. This analysis shows that "limited sovereignty" should optimally be imposed on the issuance of debt by high marginal cost countries. This analysis was based on comparative statistics, and also explored the effect of the institutional change from QMV (qualified majority voting) in the SGP to Reverse QMV in the Fiscal Compact (2012).

Finally, we closed the paper by discussing the possibility of Fiscal Integration (Fiscal Union), where a unique fiscal budgetary authority directly controls fiscal policies of all Eurozone member nations in order to internalize (free-riding) externalities among them, which means fiscal centralization as well as monetary centralization.

\section{Acknowledgements}

I would like to thank Philippe Aghion, Oliver Hart, Hideshi Itoh, Hideaki Murase, Takashi P. Shimizu, Yoshihiro Tsuranuki, Tsutomu Watanabe, and participants in seminars at the Harvard Contracts and Organization Lunch, the Harvard International Lunch, Hitotsubashi University (CTWE), Hosei University, the Japanese Economic 
Association, the Japan Association for Applied Economics, and the 16th World Congress of the International Economics Association, for their comments and discussion. I would also like to thank Harvard University for its stimulating academic environment and for the hospitality I experienced during my visiting scholarship in 2011-2012. This work was supported by a Grant-in-Aid for Scientific Research from the Japan Society for the Promotion of Science (C) No. 23530383 (2011-2013) and the Grant from the Zengin Foundation for Studies on Economics and Finance in Japan.

\section{References}

Bolton, P., \& Dewatripont, M. (2005). Contract Theory. MIT Press.

Chari, V., \& Kehoe, P. (2007). On the Need for Fiscal Constraints in a Monetary Union. Journal of Monetary Economics, 54(8), 2399-2408. http://dx.doi.org/10.1016/j.jmoneco.2007.06.032

Chari, V., \& Kehoe, P. (2008). Time Inconsistency and Free-Riding in a Monetary Union. Journal of Money, Credit, and Banking, 40(7), 1329-1356. http://dx.doi.org/10.1111/j.1538-4616.2008.00162

Coase, R. (1960). The Problem of Social Cost. Journal of Law and Economics, 3, 1-44. https://doi.org/10.1086/466560

De Grauwe, P. (2007). Economics of Monetary Union. Oxford: Oxford University Press.

Dewatripont, M. (2001). Authority. Walras-Bowley Lecture at the Econometric Society.

Grossman, S., \& Hart, O. (1986). The Costs and Benefits of Ownership: A Theory of Vertical and Lateral Integration. Journal of Political Economy, 94, 691-719. https://doi.org/10.1086/261404

Hart, O., \& Holmstrom, B. (2010). A Theory of Firm Scope. Quarterly Journal of Economics, 125(2), 483-513. https://doi.org/10.1162/qjec.2010.125.2.483

Holmström, B. (1982). Moral Hazard in Teams. Bell Journal of Economics, 13(2), 324-340. http://dx.doi.org/10.2307/3003457

Laffont, J., \& Tirole, J. (1991). The Politics of Government Decision-Making: A Theory of Regulatory Capture. Quarterly Journal of Economics, 106, 1089-1127. https://doi.org/10.2307/2937958

Suzuki, Y. (2011). A Comparative Theory of Non-Integration, Integration, and the Decentralized Firm. Journal of International Economic Studies, 25, 3-28. Retrieved from http://repo.lib.hosei.ac.jp/bitstream/10114/7051/1/J-suzuki1.pdf

Suzuki, Y. (ed.). (2010). Cross-Sectoral Comparative Analysis of Governance: A Contract \& Game Theoretic Approach. Hosei University Press (in Japanese).

Suzuki, Y., \& Tsuranuki, Y. (2017). An Incomplete Contract Approach to Eurozone Fiscal Governance" Commitment vs. Flexibility. International Economic Journal, 31, 297-309. https://doi.org/10.1080/10168737.2017.1315736

Tirole, J. (1992). Collusion and the Theory of Organizations. In J. Laffont (Ed.), Advances in Economic Theory: The Sixth World Congress. Cambridge: Cambridge University Press.

Tirole, J. (2013). What Future for the Eurozone Governance? Special Lecture at Japan Society of Monetary Economics, Hitotsubashi University, May 2013.

Tsuranuki, Y. (2005). Eurozone Finance Governance through the Stability and Growth Pact, January 2002-November 2003. Hosei Economic Review, 73(1\&2).

\section{Notes}

Note 1. The institutional description below is mainly based on Tsuranuki (2005), which pursues the institutional essence of eurozone financial governance from the viewpoint of political science. De Grauwe (2007) analyzes the costs and benefits associated with having one currency, as well as the practical issues involved with monetary union. However, this paper does not conduct contract/game theoretical analysis. We argue that the early institutional framework of the period from 2002 to 2003 was a fundamental cause undermining the credibility and effectiveness of the penalty scheme in the Stability and Growth Pact.

Note 2. Tirole (2013) considers the Euro crisis as an institutional crisis, and emphasizes the viewpoints of the incentives and interests of Eurozone member nations. Suzuki (2010) proposes a cross-sector comparative analysis of governance using a Game/Contract theoretic approach, which also considers supra-national 
governance across the Eurozone.

Note 3. The central bank of each nation can be regarded as an agent that directly implements the policy rate set by the ECB. In terms of its business organization, Suzuki (2011) referred to it as "integration", where top management gives orders and section managers simply accept and execute their orders.

Note 4. This is basically an analysis of a 45-degree line, in which financial spending (government spending) increases aggregate demand while increasing interest rates reduce aggregate demand through a decline in private investment, a reflection of the fact that they alter the equilibrium GDP.

Note 5. This is the view that an increase in financial spending and a decrease in the policy rate will lead to a growth in aggregate demand, resulting in upward pressure on commodity prices.

Note 6. The assumption $\beta>1$ means that the ECB's policy rate has a greater effect on inflation control (price stabilization of the euro) $\pi \downarrow$ than on GDP (output) $x$, which is an indicator of the real economy.

Note 7. This is an extreme hypothesis for simplification. It is possible to generalize this hypothesis to let the Ministry of Finance consider economic growth and price stability (stability of the value of the euro) as $\gamma: 1-\gamma$, where $1 / 2 \leq \gamma \leq 1$ and to let the European Central Bank consider them as $1-\gamma: \gamma$ in a weighted manner.

Note 8. This timing is due to the fact that the ECB can adjust interest rates much more quickly (every a few weeks) than each sovereign nation can adjust their fiscal policies (annually, typically).

Note 9. Dewatripont (2001) determines the optimal arrangement of the divided authority between the MOF and the Central Bank (e.g., the Bundesbank in West Germany) for one MOF and Central Bank.

Note 10. When $\beta \leq 1$, the MOF is disciplined by the ECB to an excessive extent when choosing $d$, as a higher $d$ leads the ECB to increase $i^{*}(d) \geq d$ to reduce inflation, which in turn leads the MOF to choose $d^{*}=0$ and reduces GDP output to zero. This is the "ECB-Integration" outcome (see Section 4) replicated under a divided authority structure. We eliminate the case of $\beta \leq 1$ (a corner solution case).

Note 11. The optimal fiscal spending in $\mathrm{T}=1 d_{k}^{*}, k=1,2$ is the dominant strategy for each country, irrespective of the opponent's strategy.

Note 12. This result is consistent with the economic growth in the eurozone, the increase in member nations and the accompanying gradual increase in the policy rate until the summer of 2008, that is, before the Lehman shock. The policy rate was above $4 \%$ in the summer of 2008 .

Note 13. This is a solution to the moral hazard (free-rider problem) in teams through a penalty scheme. For various forms of penalty schemes, see Bolton and Dewatripont (2005).

Note 14. The side payment here can include the non-monetary (e.g. political) support in the future from the deviating country. It provides an incentive for the compliant countries to accept the collusive (side payment) offer.

Note 15. We assume that equilibrium renegotiation is induced. The context is an international setting, making it an "incomplete contract" situation. Therefore, "equilibrium renegotiation" would be more natural than "renegotiation-proof".

Note 16. As $\alpha$ is the marginal cost parameter for the issuance of public debt, $\alpha_{H}$ indicates a high marginal cost country, while $\alpha_{L}\left(\leq \alpha_{H}\right)$ indicates a low marginal cost country for the issuance of public debt.

Note 17. The modeling is based on actual experiences in 2002 and 2003 when the major low marginal cost powers (Germany and France) failed to abide by the SGP's fiscal rule.

Note 18. As $\alpha_{L} \leq \alpha_{H}$, the inequality $\Delta_{L}>0$ tends to hold. This implies that the major powers with smaller marginal costs $\alpha_{L}<\alpha_{H}$, such as Germany and France, could easily block the imposition of sanctions through collusion (the formation of a blocking coalition) among eurozone countries before the vote at the Financial Ministers Council. Thus, an asymmetry in $\alpha_{L}$ and $\alpha_{H}$ is essential to this argument.

Note 19. This idea is based on Tirole (1992) and Laffont and Tirole (1991). If $\xi=0$, we can attain the first best efficiency, just similar to the Coase theorem (1960). In our international setting especially, a negotiation or persuasion setting, the transaction cost $\xi>0$ is a natural assumption.

Note 20. Remember that the inflation rate is formulated as $\pi=x-\beta i$.

Note 21. Consider the effect of an institutional change from QMV in the SGP to Reverse QMV in the Fiscal 
Compact (2012) referred to in the introduction. The Reverse QMV implies an increase in the penalty for deviating countries. However, the Fiscal Compact still leaves room for ex-post renegotiation. The analysis in this section suggests that the Fiscal Compact (2012) could implement more rigid fiscal discipline than the SGP.

Note 22. Suzuki and Tsuranuki (2017) analyze the Second Eurozone Crisis in 2015 by using an incomplete contract framework, and reveals the conflict of interests between the European Commission (Germany) and Greece over the Greek debt repayment plan, from the viewpoint of austerity vs. pro-growth.

Note 23. See, Hart and Holmstrom (2010) and Suzuki (2011).

Note 24. "Brexit" (exit of the Britain from the EU ) could be interpreted from this point of view (the loss of political benefits due to the loss of sovereignty was large enough to lead the Britain to exit from the EU which was economically beneficial).

\section{Copyrights}

Copyright for this article is retained by the author(s), with first publication rights granted to the journal.

This is an open-access article distributed under the terms and conditions of the Creative Commons Attribution license (http://creativecommons.org/licenses/by/4.0/). 